\title{
Appendix 1: Methodological choices
}

This appendix details some of the methodological choices made in the empirical chapters of the book. Although there is variation in the data and methods used throughout the book, there is also some substantial overlap, as semi-structured interviews are the main method used in the empirical chapters. The empirical chapters use data from the interviews to develop a deeper understanding of the practices and processes of socialization that currently exist in the European Union (EU) foreign and security policy. In total, the book draws on 79 interviews conducted between 2015 and 2021. ${ }^{1}$ The list of respondents is found in Appendix 3. As we explain in Chapter 4, we conducted interviews because we believe they reveal how practitioners themselves understand their everyday practices. That is, if we try to explain the meaning behind a practice without using the language of practitioners, we risk explaining a different practice than the one that actually exists in the community of practice that we are studying. This perspective is also known as the internalist view of practices.

However, this choice also has some drawbacks. For example, if we only use the language of practitioners to reveal the constitutive rules for a certain practice, we risk overlooking taken-for-granted practices, as the practitioners often do not reflect on these practices even when asked about the main informal norms and rules that structure their work. The optimal solution to this problem would be to combine our interviews with ethnographic fieldwork and immerse ourselves in the practitioners' context before conducting our semi-structured interviews (Nair, 2021). Although we were not able to conduct prolonged ethnographic fieldwork, it can be argued that the authors of this book are sufficiently immersed in or 'enculturated' through previous work experiences (Spradley, 1979) in the relevant context to identify potential practices that can be probed during an interview. For example, one of the authors has extensive work experience with the European Commission, and one has worked with coordinating Sweden's positions in the Political and Security Committee (PSC) at the Swedish Ministry for Foreign Affairs. The two other authors have conducted prolonged field research in Brussels. Overall, the four authors have studied the dynamics of the Common Foreign and Security Policy (CFSP) for many years before writing this book, and therefore have immersed themselves

1 One interview was conducted in 2015, and the rest between 2016 and 2021. 
in the context of research on EU foreign and security policy. That is, these experiences should decrease the risk that we ask the wrong questions simply because we do not have a sufficient understanding of the context in question before conducting the interviews for this book.

To increase the comparability of the empirical chapters, we used a common interview guide when conducting interviews (see Appendix 2). Although some of the chapters are based on interviews that have been specifically conducted for the purposes of this book (Chapters 5, 8 and 9), other chapters also use interviews that have been conducted in previous research projects (Chapters 6 and 7). The questions asked in the interviews for these previous research projects have largely inspired the development of the joint interview guide and therefore are not substantially different.

An additional challenge of conducting interviews with national representatives of international institutions such as the EU is that respondents often only accept interview requests on the condition of anonymity. For this reason, all respondents were promised anonymity on the basis that they could be included in a list of respondents and that their names or member states would not be tied to any specific quotation. As a result, the respondents are referred to in the text by the CFSP body and respondent; for example, COEST 2 . The numbers used for each respondent have also been randomized to ensure anonymity.

A final drawback of semi-structured interviews is the risk of a potential bias in terms of the respondents who accept the interview request. In other words, the respondents who agree to an interview may not represent the views of the whole group. For the most part, this has not been an issue for the interviews conducted for this book. When the population of potential respondents was member state representatives (Chapters 5, 6 and 8), there was considerable variation in terms of geography (member states from both the North and South as well as the East and West) and population/size (both large and small member states). However, as not all empirical chapters used the same data or methods, the next section describes the specific choices and issues related to the data and methods used for each chapter, including the risk of a biased sample of respondents.

\section{CHAPTER 5: PRACTICES AND CONTESTATION MANAGEMENT IN CFSP COUNCIL WORKING GROUPS}

Similar to most other empirical chapters in this volume, the main data source for Chapter 5 is a set of interviews with representatives to two Council Working Groups (CWGs): the Working Party on Eastern Europe and Central Asia (COEST) and the Politico-Military Group (PMG). In total, 12 interviews were conducted between October and November 2020. One of the interviews 
was conducted as a group interview with two representatives from a single member state (at the request of the representatives). For purposes of anonymity, this interview has been treated as two interviews: each of the respondents were assigned their own code. For this reason, the interview material consists of 13 unique respondents. All interviews were semi-structured, as an interview guide was used although not strictly followed. The interviews lasted between 45 and 60 minutes, and, given the author's inability to travel to Brussels due to the COVID-19 pandemic, all interviews were conducted via videoconferencing software such as Skype, Zoom, Teams or Webex.

In addition to the interview data, Chapter 5 uses data from the Negotiations in the Council of the European Union (NCEU) dataset - a telephone survey conducted once every three years (2013-2018) by researchers at the Centre for European Research at the University of Gothenburg (CERGU) (Naurin et al., 2020). The survey targets representatives from 11 working groups. Two of these are part of the CFSP decision-making hierarchy: the PSC and the PMG. Therefore, the dataset allows for some descriptive comparisons between these groups, which are presented and discussed in the chapter. Given the high response rate to the survey, the data for both groups are quite substantial. Of the 300 potential respondents (150 in each group) between 2003-2018, 121 telephone interviews were held with PMG representatives and 117 with PSC representatives, giving an average response rate of 79.3 per cent for the two groups. The data have been analysed using a standard t-test for all 176 variables included in the dataset. The statistically significant $(P<0.05)$ differences of the means between the two groups are presented in Table 5.1 in Chapter 5 .

The following section summarizes the variables referred to in Table 5.1. Cooperation scores (included in the surveys conducted 2003-2018) are based on the following question: Which member states do you most often cooperate with in order to develop a common position? Points are assigned depending on the order in which the most frequent partners (1-10) are mentioned: first position equals 10 points, second position equals 9 points, and so on. Similarly, influence scores (included 2012-2018) are based on the following question: In general, which member states have the greatest potential to influence the positions you take during the discussions? The first member state mentioned is assigned 10 points, the second member state 9 points, and so on. Although using the same scale, 'Infl2_ms' measures the perceived influence that one's own member state has on other member state's positions. Number of years in Brussels (included 2009-2018) is measured as the number of years that the respondent has represented their country in EU working groups and committees, rounded to the nearest 0.5 years. Risk aversion (included 2015) is the combined treatment and control groups of a vignette experiment; the treatment group members were asked if they would accept or reject a compromise proposal in a situation where 'the stakes are very high' on a scale from $0-10$, 
where 0 corresponds to absolutely rejecting the proposal, and 10 to absolutely accepting the proposal. The control group were asked the same question but informed that the issue was simply of high importance to their member state. The PMG had a mean score higher than the PSC for both the treatment and control groups. The largest difference between the PSC and the PMG was in the treatment group (mean difference $=2.322$ ). In addition, the difference between the groups regarding another question on the perceived frequency of high-stakes negotiations in their respective group was also relatively large (mean difference $=0.694$ on a scale from 0 to 10 ), although the difference was only statistically significant at the 10 per cent level $(P<0.1)$. The differences between the groups regarding these two variables are summarized in Figure 5.3 in Chapter 5. Finally, the effect of Brexit (included 2018) was based on this question: The fact that the United Kingdom is leaving the EU, to what extent does it affect your choice of cooperation partners? The following answer alternatives were provided: $0=$ to a very small extent; $10=$ to a very large extent; and $5=$ neither small nor large. More information about the dataset can be found at https://snd.gu.se/en/catalogue/study/snd1143.

\section{CHAPTER 6: PRACTICES AND PERSUASION IN THE POLITICAL AND SECURITY COMMITTEE}

This chapter is based on 25 interviews with representatives and deputy representatives to the PSC conducted between 2016-2019. Of the 25 interviews, three were conducted via telephone. The interviews were semi-structured and usually lasted around 40 minutes: 17 of these interviews were recorded and transcribed, and 23 were documented by taking notes as these respondents did not wish to be recorded. The interviewees were from large and small and old and new EU member states, which should rule out the possibility of a selection bias.

\section{CHAPTER 7: THE EUROPEAN EXTERNAL ACTION SERVICE: A MELTING POT OF EU FOREIGN POLICY PRACTICE}

Chapter 7 is based on 27 interviews with officials in the European External Action Service (EEAS) conducted between 2015 and 2021. A majority of interviews were conducted face-to-face in Brussels, three were conducted via telephone call, and four were conducted via video call. The interviews were semi-structured and lasted between 30 and 80 minutes. The telephone interviews were shorter than the face-to-face interviews and the video interviews. Six interviews were conducted in groups (groups of two officials interviewed at the same time), which provided more opportunities for the officials to 
reflect on common practices. Only nine of the interviews were recorded, and all interviewees were assured anonymity and were offered the option not to be recorded in exchange for greater openness. Those interviewed were selected on the basis of their insights into the general development of the EEAS. Eight of the interviewees had specific insights into the strategic communications development discussed in the final analytical part of the chapter. A majority were career diplomats and EU civil servants (from a variety of member states), and five were seconded national experts.

\section{CHAPTER 8: DIPLOMATIC PRACTICES BEYOND BRUSSELS: THE EU DELEGATIONS AND THE COORDINATION OF EU FOREIGN AND SECURITY POLICY}

This chapter is based on ten interviews with diplomats in the EU delegations and EU member state embassies in Washington, Beijing and Seoul between November and December 2019. One of the ten interviews was conducted via telephone. The interviews were semi-structured and lasted between 45 and 90 minutes. The respondents were from large and small and old and new EU member states.

\section{CHAPTER 9: EU MISSIONS AND OPERATIONS}

Chapter 9 is based on a qualitative survey circulated among the key units involved in the planning, implementation and assessment of CSDP missions and operations. The survey was conducted in March and April 2021 and contained one background question and five questions about lesson learning (see Appendix 4). The survey targeted key persons from the following units: the Political and Security Committee (PSC), the Politico-Military Group (PMG), the Committee for Civilian Aspects of Crisis Management (CivCom), the Crisis Management and Planning Directorate (CMPD), the Civilian Planning and Conduct Capability (CPCC), the Security and Defence Policy Directorate (SECDEFPOL), the Military Planning and Conduct Capability (MPCC), the European Union Military Committee (EUMC), the European Union Military Staff(EUMS), the European Defence Agency (EDA), the Integrated Approach for Security and Peace Directorate (ISPD), the European Institute for Security Studies (EUISS), the European Union Satellite Centre (SATCEN) and the European Security and Defence College (ESDC). We sent one reminder. Of the 11 targeted units, we received nine survey responses from eight units (no response from EDA, SECDEFPOL and SATCEN). This is considered a high response rate, and the text responses provided a rich account of the lessons learning process across all units. All respondents from units within the EEAS 
are referred to as 'EEAS officials' and within the Council as 'Council representatives' to guarantee anonymity (otherwise persons in charge of the lessons learning process in each unit are easily recognized). We also conducted two in-depth group interviews (groups of two officials interviewed at the same time) with key personnel in the EEAS working within the Integrated Approach for Security and Peace Directorate (ISPD) in 2020 and 2021. 